\title{
A diferença em outros contextos: profissionais transexuais com ensino superior inseridos no mundo do trabalho
}

\author{
Denise Macedo Ziliotto ${ }^{1}$ \\ Universidade La Salle (Canoas, RS, Brasil) \\ Simone Maria Davies \\ Universidade La Salle (Canoas, RS, Brasil) \\ Cintia Itaqui ${ }^{3}$ \\ Universidade La Salle (Canoas, RS, Brasil)
}

$\mathrm{O}$ artigo tem como objetivo analisar narrativas de profissionais transexuais acerca de suas experiências no mundo do trabalho. Com esse intuito, foi desenvolvida pesquisa qualitativa exploratória, realizada por meio de entrevistas com três mulheres transexuais e um homem trans, que possuem vínculos formais de trabalho em empresas e são residentes em diferentes cidades brasileiras. A coleta de dados, submetida à análise de conteúdo, identificou que a empregabilidade dos profissionais se relaciona com aspectos como escolaridade e raça. A não identificação da transexualidade no ambiente laboral é percebida como um facilitador, em razão da passibilidade e cisnormatividade dos corpos; contudo, foram vivenciadas situações de discriminação em razão de atitudes transfóbicas em processos seletivos e no contexto laboral. A mudança no registro civil e a abertura à diferença nas empresas são defendidas pelo/as participantes como decisivas, assinalando-se como questões estruturais a importância de ações afirmativas que incidam no âmbito educacional e no mundo do trabalho.

Palavras-chave: Inclusão, Gênero, Mercado de trabalho, Transgênero.

The difference in other contexts: transsexual professionals with higher education in the world of work

The article aims to analyze transsexual professionals narratives about their experiences in the world of work. In order to do this, a qualitative research with exploratory approach was developed. It was carried out through interviews with three transsexual women and one transgender man who have employment relationships in companies and live in different Brazilian cities. Data collection, submitted to content analysis, identified that professionals employability is related to aspects such as schooling and race. The non-identification of transsexuality at work is perceived as a facilitator, due to the passability and cisnormativity of bodies; however, situations of discrimination were experienced due to transphobic attitudes in selection processes and in the work context. The change in civil registration and opening to difference in companies are defended as decisive by the participants, who pointed out the importance of affirmative actions focused on education and the world of work as structural issues.

Keywords: Inclusion, Gender, Labor market, Transgender.

https://orcid.org/0000-0001-9146-5425

https://orcid.org/0000-0001-7782-5658

https://orcid.org/0000-0003-4245-9904 


\title{
Introdução
}

\begin{abstract}
$A_{p}^{h}$ homofobia, a transfobia e o racismo são estruturais no Brasil, estabelecendo-se mediante práticas e normas institucionais que legitimam desigualdades sociais em função da raça e/ou da sexualidade heterocisdiscordante. "Do ponto de vista histórico e cultural, são identificados privilégios para brancos, héteros e cisgêneros, em oposição à exclusão de minorias como negros, homossexuais, travestis e transexuais, da participação em instituições sociais" (Benevides \& Nogueira, 2020, p. 69).
\end{abstract}

Nogueira (2017) explicita que a maioria das pessoas trans - travestis e transexuais - no país enfrenta a miséria e exclusão social, sem acesso à educação, saúde, qualificação profissional, oportunidades no mercado de trabalho formal e políticas públicas voltadas para suas demandas específicas: "O não reconhecimento das identidades trans, o abandono familiar, a evasão escolar, a precarização laboral, a exclusão do mercado de trabalho concorrem para a marginalização dessa população" (p. 22).

Em diferentes dimensões - escolarização, laços familiares, cuidados, mundo laboral evidenciam-se que experiências como a violência doméstica, a rua como via de sobrevivência, a evasão escolar, a redução das oportunidades de trabalho, agravadas pelo controle sobre os corpos por meio de normativas não permitem a presença de pessoas trans em espaços predeterminados pelo sistema vigente (Oliveira et al., 2018).

O I Encontro Nacional de Travestis e Transexuais de Luta contra a AIDS (ENTLAIDS), ocorrido em 2004, é um dos marcos da consolidação da organização política de travestis e transexuais no país (Prado, 2016). Contudo, essa mobilização não assegurou mudanças significativas na condição dessa população, pois o país continua como aquele mais mata travestis e transexuais no mundo ${ }^{4}$, passando do 55을 lugar em 2018, para o 68으 em 2019 no ranking de países seguros para a população LGBTQIA+. Em 2019 houve 124 assassinatos de pessoas trans pelo Brasil, sendo que 121 das vítimas eram travestis e mulheres trans e outros três foram identificados como homens transgênero; $67 \%$ dos crimes foram cometidos contra prostitutas, sendo que $64 \%$ dos casos aconteceram na rua, e os autores não conheciam ou tinham relação direta, social ou afetiva com a vítima (Benevides \& Nogueira, 2020).

Em 2020, de janeiro a outubro, foram identificados 151 assassinatos de travestis e trans (Associação Nacional dos Travestis e Transexuais [ANTRA], 2020), significando uma alta de 22\% em relação ao mesmo período de 2019 , sendo que somente $7 \%$ dos suspeitos de 124 crimes foram presos. Em 2018, foram 163 pessoas trans assassinadas no Brasil, das quais 82\% eram pretas e pardas, explicitando ainda a interseccionalidade pela discriminação por gênero e raça, pois a população trans negra é a que tem as maiores chances de ser assassinada no Brasil (Benevides \& Nogueira, 2019).

A condição desse grupo no contexto educacional brasileiro também é preocupante: a Pesquisa Nacional sobre o Ambiente Educacional no Brasil realizada pela Associação Brasileira de Lésbicas, Gays, Bissexuais, Travestis e Transexuais (ABGLT, 2018) apontou que 56\% dos entrevistados/as foram assediados/as sexualmente na escola, 73\% afirmam ter sido ofendidos/as e $27 \%$ sofrido agressões físicas no contexto educativo em função de sua orientação sexual. Andrade (2012) denuncia que "a maioria das políticas públicas direcionadas a travestis e transexuais é direcionada para a prevenção de doenças e o combate à exploração sexual, e não para políticas de inclusão na escola e no trabalho" (p. 226), o que reafirma a exclusão recorrente nos contextos da educação e do mundo laboral.

4 Terceiro ano consecutivo, segundo dossiês analisados (Associação Nacional de Travestis e Transexuais, 2018; Benevides \& Nogueira, 2020, 2019). 
No âmbito da luta pelo direito ao trabalho e renda, pequenos avanços ocorridos em relação à presença de pessoas trans em empregos formais de diversos setores evidenciam possibilidades de ascensão de carreira e iniciativas no empreendedorismo apontam perspectivas positivas. Contudo, no ano de 2020, ocorreram muitos retrocessos: contingenciamento de verbas para a saúde e educação no âmbito federal, as reformas trabalhista e previdenciária contribuindo para o aumento do desemprego, da pobreza e da informalidade, e o aumento da violência contra a população LGBTQIA +. A estimativa é de que apenas $4 \%$ da população trans feminina ocupe empregos formais, e somente $6 \%$ esteja em atividades informais e subempregos, mantendo-se o dado de que $90 \%$ da população de travestis e mulheres transexuais têm a prostituição como fonte de renda (Benevides \& Nogueira, 2020).

Considerando a importância de promover "a saúde, a pesquisa, a educação, o respeito, a dignidade e igualdade de direitos para as pessoas trans e com variabilidade de gênero em todos os aspectos culturais" (World Professional Association for Transgender Health, 2012 p. 1), avalia-se ser relevante a visibilidade de experiências de profissionais neste âmbito.

Diante desse panorama, o objetivo da investigação apresentada é analisar narrativas de profissionais transexuais com vínculos formais de trabalho, pois conhecer as experiências dos sujeitos nesse âmbito pode contribuir para a visibilidade dessas vivências, possibilitando a reflexão acerca das relações e das oportunidades profissionais para pessoas trans. A investigação desenvolvida tem delineamento qualitativo e exploratório, e a coleta de dados foi realizada por meio de entrevistas com três mulheres transexuais e um homem trans. Inicialmente, serão apresentados marcadores teóricos que norteiam a investigação empírica realizada, identificando questões atinentes à temática pesquisada.

\section{Problematizando as temáticas de gênero e trabalho}

O termo cisgênera - prefixo latino "cis" - indica coisas que se mantêm, em que não há mudanças de propriedade. Em sua indicação relativa à identidade de gênero, refere-se às pessoas que mantêm a identidade de gênero atribuída ao nascer, ou a congruência entre esta e suas características corporais compreendidas como presentes em determinado gênero. Portanto, cisgênera diz respeito à estabilidade e ao pertencimento a um rol de parâmetros de gênero definidos. Em contraponto, "trans" significaria mudança, trânsito ou transformação desses parâmetros. Dessa forma, cisgênera e transgênera são usados para designar pessoas nas quais o "sexo biológico" e o "sexo psicológico" estão ou não conformados ou alinhados, de acordo com parâmetros de gênero definidos. Importante problematizar estas denominações que se colocam a partir de uma normatividade, na qual os sujeitos transgêneros seriam desviantes, fora da norma (Almeida \& Vasconcellos, 2018). Nesta investigação, concebemos que a "identidade de gênero refere-se à experiência interna e individual de cada pessoa" (Conselho Federal Psicologia, 2018, p. 2), refutando a heteronormatividade. De forma ampliada, a condição transgênera remete àquelas pessoas que não se identificam com o gênero atribuído no nascimento, nomeadamente travestis, mulheres e homens transexuais, transmasculinos e demais pessoas trans ${ }^{5}$.

5 Travestis: Pessoas que foram identificadas como sendo pertencentes ao gênero masculino no nascimento, mas que se reconhecem como pertencentes ao gênero feminino e têm expressão de gênero feminina, mas não se reivindicam como mulheres da forma com que o ser mulher está construído em nossa sociedade. Mulheres Transexuais: Pessoas que foram identificadas como sendo pertencentes ao gênero masculino no nascimento, mas que se reconhecem como pertencentes ao gênero feminino e se reivindicam como mulheres. Homens Trans: São aquelas pessoas que foram identificadas como sendo pertencentes ao gênero feminino no nascimento, mas que se reconhecem como pertencentes ao gênero masculino e se reivindicam como homens. Transmasculinos: São aquelas pessoas que foram identificadas como sendo pertencentes ao gênero feminino no nascimento, mas que se reconhecem como pertencentes ao espectro do gênero masculino, têm expressão de gênero masculina, mas não se reivindicam da forma com que o ser homem está construído em nossa sociedade (Benevides \& Nogueira, 2020, p. 11). 
Milskosci e Pelúcio (2007) enfatizam que a luta de diversos movimentos sociais passa pela problematização do humano, explicitando os conflitos, as inconformidades e as instabilidades das normativas sociais. Para Vianna (2015), o movimento LGBTQIA+ tem grande importância por abranger idealizações de diferentes grupos e, com suas reivindicações, conseguir estabelecer negociações que gerem políticas públicas. Dentre as conquistas, está a mudança do nome civil, que, segundo Bento (2014), é uma questão fundamental para os/as transexuais, por não se reconhecerem pelo nome de registro, não pertencendo ao gênero masculino ou feminino. No Brasil, é permitido alterar o nome de registro para o nome social ${ }^{6}$, a partir do requerimento em instituições públicas, passando a pessoa a ser chamada pelo nome com o qual se identifica. Anteriormente, ao solicitar essa mudança nos documentos de registro civil, era necessário um processo judicial, tendo como requisitos laudos psicológicos e médicos, bem como depoimentos de testemunhas. Por decisão do STF em 2018 (STF, 2018), foi legitimado direito a transgêneros ${ }^{7}$, que assim o desejarem independentemente da cirurgia de transgenitalização ou da realização de tratamentos hormonais ou patologizantes, à substituição de prenome e sexo nos cartórios de registro civil, não necessitando autorização judicial.

A luta pela visibilidade e garantia de direitos das pessoas trans também se apresenta no mundo do trabalho. Assim como outras minorias, os gays, as lésbicas, as travestis e os/as transexuais, são alvos constantes de discriminação no ambiente de trabalho. Muitas empresas propagam ter uma política de inclusão da diversidade, mas o que se verifica são muitas contradições: algumas empresas buscam status para a construção de uma imagem de socialmente responsável quando, na prática, nenhuma ação verdadeiramente de inclusão é observada (Diniz et al., 2013; Carreiri et al., 2014).

Mesmo na esfera pública, há ações que não observam a equidade de oportunidades para as/os trabalhadoras/es, como a investigação de Teixeira (2012), que descreveu a histórias de vida de uma profissional que teve o final da carreira militar determinada em função do diagnóstico de transexualismo. Decorrente do parecer da junta médica em processo de perícia, foi indicada aposentadoria por invalidez, ao ser julgada incapaz definitivamente para o serviço militar:

o lugar abjeto que ela passou a ocupar quando desestabilizou as normas do gênero, materializando no corpo as ideias de que a biologia não aprisiona o gênero, que gênero está deslocado do sexo e que a reprodução não sustenta a heterossexualidade. Enfim, essa visibilidade tornou-se ameaçadora ao evidenciar que as normas militares são insuficientes para a produção de um cidadão militar masculino (pp. 505-6).

Prado (2016) constata que, notadamente a partir de 2004, travestis e transexuais ocuparam mais espaços institucionais como vereanças, assembleias legislativas e lugares do poder executivo. Nas eleições de 2016, houve 94 candidaturas de pessoas trans em 22 dos 26 estados, embora somente 6 tenham sido eleitas. Nas eleições de 2020, das 94 candidaturas trans inscritas, 25 se elegeram, representando um aumento de 212\% em comparação a 2016. Entre as eleitas, 24 são mulheres trans e travestis e um é homem trans, sendo que sete das 24 ocupam o lugar de mais votadas em suas cidades e 35\% são negras. Há algumas conquistas significativas, como a travesti Duda Salabert (PDT), que foi a vereadora que obteve mais votos na história de Belo Horizonte (MG), e de Carolina Iara de Oliveira, coparlamentar da Bancada Feminista do PSOL em São Paulo, primeira pessoa intersexo eleita (Sexuality Policy Watch, 2020).

6 Decreto № 8727 de 28 de abril de 2016 que dispóe sobre o uso do nome social no Brasil: https://presrepublica.jusbrasil.com.br/legislacao/330064041/decreto-8727-16

7 Designação usada no documento analisado. 
Siqueira et al. (2009) defendem que é obrigação das organizações lutarem contra a discriminação - referindo-se a grupos sociais como negros, deficientes e LGBTQIA $+{ }^{8}-$, uma vez que possuem papel importante na sociedade, assim como a família e a escola, constituindo-se como locais onde os sujeitos trabalhem e estabeleçam relações. $\mathrm{O}$ combate à discriminação é defendido pelos autores tanto em nível interno como externo, pois, muitas vezes, a violência se evidencia pela omissão daqueles que podem fazer algo para combater ou punir e não o fazem, como é o caso de gestores e do setor de Recursos Humanos.

Rondas e Machado (2015) realizaram investigação relativa à inserção de profissionais travestis no mundo do trabalho, tendo identificado que, em sua maioria, as áreas de beleza e estética (setor comércio e serviços) têm proporcionado maior empregabilidade e geração de renda. Contudo, a maioria das entrevistadas enfrentava importante "instabilidade profissional, de ocupação ou de emprego" (p. 197). Os autores assinalam que "quanto maior o número de alternativas que as travestis encontram para traçar suas estratégias de inserção profissional, maior sua percepção com relação à liberdade pessoal de agir em face das pressões do ambiente social e de empregadores" (p. 203).

Diniz et al. (2013), em estudo com profissionais homossexuais, identificaram que, mesmo com a adoção das políticas de diversidade nas organizações, há direitos e oportunidades distintos dos oferecidos aos heterossexuais, além de outras violências, configurando-se incongruências entre o discurso empresarial e as práticas de gestão. Afirmam ainda que, mesmo quando transexuais, travestis, gays ou lésbicas conseguem um emprego, além de todos os assédios sofridos diariamente, a possibilidade de desenvolvimento profissional também é limitada. Observam que as/os profissionais não recebem oportunidades de crescimento, nem ocupam cargos em nível gerencial - e, muitas vezes, são mantidas/os em funções que não têm contato com o público externo.

A primeira mulher trans a possuir registro na OAB/RJ - a advogada e ativista Maria Eduarda Aguiar - considera essencial a capacitação das empresas e da área de Relações Humanas para que ocorra a inserção das pessoas trans nas organizações. Ela afirma que a discriminação presente no mercado de trabalho e o desconhecimento relativo às questões de diversidade são as principais dificuldades enfrentadas para estabelecer um ambiente saudável para as pessoas trans. Em relação aos/às profissionais que estão empregados/as, os principais empecilhos remetem aos usos do nome social e do banheiro, reconhecendo a passabilidade como um fator infelizmente decisivo na empregabilidade da população trans (Caroilovsky, 2020).

A passividade refere-se a como uma pessoa transgênera pode ser lida como pessoa não-trans em seu biotipo, roupa, gestos, atitudes, pois corresponde aos estereótipos de gênero existentes. "Passar" é ser reconhecida/o na vida cotidiana como alguém que está de acordo com as normas de gênero. Trata-se de uma forma de proteção, pois as pessoas trans com passabilidade ficam menos expostas à violência física e simbólica, já que não são reconhecidas por manifestações de gênero desviantes (Lucena, 2018). Benevides e Nogueira (2020) empregam a expressão Leitura Social Cisgênera para designar essa questão, referindo-se "àquelas pessoas que devido a sua expressão de gênero, aliada a atributos físicos e outros elementos, são entendidas como se fossem pessoas cisgêneras" (p. 37).

8 L, G, B: as três primeiras letras tratam a respeito da orientação sexual. O L se refere às lésbicas e o G aos gays, ou seja, mulheres e homens, respectivamente, que sentem atração afetiva e/ou sexual por pessoas do mesmo gênero que o seu. Já o B inclui as pessoas bissexuais, que têm essa atração por ambos os gêneros. T: tal letra abrange as identidades de gênero, sendo elas transgêneros, transexuais e travestis. Essas pessoas se identificam com um gênero diferente do que foi designado em seu nascimento. Além disso, é o oposto de cisgênero, que são homens e mulheres que se reconhecem conforme seu gênero de nascimento. Q: o Q vem de queer, que são as pessoas que transitam entre os gêneros feminino e masculino ou que não seguem a binaridade masculino-feminino (não binário). I: já o I fala sobre o intersexual, que são pessoas cujo desenvolvimento sexual corporal é não binário, então não se encaixa na lógica masculino-feminino. A: o A também aborda os assexuados, que não sentem atração sexual por outra pessoa, apesar de a afetiva ainda existir. +: e o que é o símbolo + ? São todas as inúmeras outras possibilidades de orientação sexual e identidade de gênero. Um exemplo são os pansexuais, aqueles que sentem atração afetivo-sexual independente da identidade de gênero (https://catracalivre.com.br/cidadania/glossario-lgbtqia-entenda-cada-letra-da-sigla-e-termos-comuns/). 
Considerando esse panorama, que aponta conquistas concomitantes às experiências de discriminação e impedimentos no âmbito profissional, foi desenvolvida a investigação que busca responder à seguinte questão de pesquisa: Como os/as profissionais transexuais, inseridos/as em empresas, vivenciam experiências no mundo do trabalho?

\section{Método}

O presente artigo refere-se a uma pesquisa de cunho social, conformando-se como investigação de natureza qualitativa que, segundo Flick (2013), visa captar significados subjetivos a respeito da questão proposta, a partir das perspectivas das/o participantes, nessa investigação, os profissionais transexuais.

A investigação é de caráter exploratório e tem a finalidade de investigar o mundo do trabalho para mulheres e homens transexuais, buscando contribuir para a visibilidade de questões que estão implicadas nesse contexto. Como instrumentos de coleta de dados, foram utilizadas entrevistas semiestruturadas, que se configuram como uma das ferramentas mais utilizadas quando se trata de pesquisas sociais, por meio da qual é possível obter dados de diversos aspectos da vida social e de forma mais aprofundada (Gil, 2012).

A pesquisa teve como participantes quatro profissionais de diferentes cidades brasileiras das regiões sul e sudeste, selecionados/as por conveniência, mediante indicações de contatos pessoais dos pesquisadores e uma indicação de entrevistada. Foram feitos sete convites a pessoas trans, sendo obtidos o aceite de quatro; foi decisiva para a adesão a confirmação da proximidade entre o mediador do contato e a entrevistadora para um dos sujeitos e, em outra situação, questionamentos a partir de várias trocas de mensagens prévias, que assegurassem a credibilidade da investigação. A preocupação com o anonimato também foi expressa como condição central para outro profissional, configurando aspectos que revelam o quanto a identidade trans e a análise da temática proposta aos participantes envolvem possíveis tensões e impasses, o que contingenciou também as entrevistas no desenvolvimento dos assuntos propostos, circunscritos pela abordagem das experiências de trabalho.

Os critérios de inclusão estabelecidos definiram como exigência: identificação do participante como pessoa trans, consentimento em participar da investigação e vinculação a emprego formal. As entrevistas gravadas em áudio foram transcritas e, posteriormente, realizadas várias leituras para apropriação do conteúdo.

As autoras do artigo são cisgêneras, filiadas a uma instituição de ensino superior comunitária e confessional, uma com atuação no âmbito acadêmico e outra em empresa multinacional, na área de Recursos Humanos, o que situa o lugar do qual são realizadas as leituras e análises atinentes à investigação realizada. As entrevistas foram examinadas a partir do sentido, perfazendo leituras transversais, como indica a análise de conteúdo proposta por Bardin (2010). As três previstas - préanálise, exploração dos achados e tratamento dos resultados - possibilitaram encontrar as unidades de sentido que compuseram as categorias, desenvolvendo a discussão dos dados que respondem ao objetivo da investigação, apresentada a seguir.

\section{As vivências do/as profissional/is trans}

A apresentação e análise dos dados evidenciam os resultados obtidos na pesquisa, propiciando compreender o contexto das/o profissionais transexuais no mundo do trabalho e sua interface nas organizações. A seguir são apontados os/as entrevistados/as e suas características pessoais e profissionais:

Ana - 34 anos, branca, bacharel em Psicologia, psicóloga, 10 anos atuação profissional; 
Betina - 48 anos, branca, bacharel em Turismo e Hotelaria, operadora de caixa, 2 anos na empresa atual;

Carla - 28 anos, branca, curso Análise e Sistemas incompleto, analista de sistemas, 8 anos de atuação profissional;

Daniel - 26 anos, negro, bacharel em Administração, microempresário, 7 meses na empresa atual.

A idade média das/o entrevistadas/o é de 34 anos, morador/as de diferentes cidades do Brasil, e todas/o possuem ensino superior, realizaram cirurgia de redesignação sexual e retificaram seu nome de registro civil. A evidência inicial da escolarização universitária aponta a possível potencialidade da empregabilidade, condição pouco presente na população trans. Benevides e Nogueira (2020) assinalam que, devido à exclusão familiar, a saída de casa de travestis e mulheres transexuais ocorre em média aos 13 anos, há implicações na continuidade da escolarização. Os indicadores apontam que, nessa população, somente $0,02 \%$ estão na universidade, $72 \%$ não possuem o ensino médio e $56 \%$ o ensino fundamental, repercutindo na dificuldade de inserção no mercado formal de trabalho e na qualificação profissional. Identifica-se também a possível incidência do recorte por raça, pois há somente um entrevistado negro, reduzindo a interseccionalidade da discriminação vivenciada pelas profissionais. Akotirene (2019) afirma a "inseparabilidade estrutural do racismo, capitalismo e cisheteropatriarcado 9 - produtores de avenidas identitárias em que mulheres negras são repetidas vezes atingidas pelo cruzamento e sobreposição de gênero, raça e classe" (p. 14).

A análise da pesquisa foi realizada a partir do estabelecimento de três categorias: As transformações no corpo e a importância do nome social para a inserção profissional, percursos profissionais e discriminação nas vivências de trabalho, apresentadas a seguir.

\section{As transformações no corpo e a importância do nome social para a inserção profissional}

Nesta categoria, são compartilhados relatos acerca do processo de transformação do corpo em função da transexualidade e o impacto das mudanças na vida profissional, questões trazidas pelas/o entrevistadas/o:

. . . Tive sorte de nascer dessa forma, com traços não tão masculinos, ou seja, tenho as mãos e pés pequenos, estatura baixa, o que me facilita muito circular por qualquer lugar sem que se note alguma diferença, sem que desconfiem que sou trans. Desde cedo, quando me entendi por gente, já sabia que havia algo diferente, então, conforme fui crescendo, isso foi acentuando mais. Assim que pude já procurei me informar sobre como fazer a cirurgia de redesignação sexual e, também, as próteses mamárias. Além disso, fiz uma cirurgia para afinar o nariz (Ana, 8 de novembro de 2017).

Betina também realizou cirurgia e relata:

... desde cedo, quando saí do Brasil e fui morar na Europa, já me chamavam pelo nome feminino, embora eu aparentasse ser um homem. ... Ao longo dos anos, eu fui mudando minha aparência,

9 O patriarcado é um sistema político modelador da cultura e dominação masculina, especialmente contra as mulheres. É reforçado pela religião e família nuclear que impõem papéis de gênero desde a infância baseados em identidades binárias, informadas pela noção de homem e mulher biológicos, sendo as pessoas cisgêneras aquelas não cabíveis, necessariamente, nas masculinidades e feminilidades duais hegemônicas. A despeito do gênero atribuído socialmente, pessoas não-cis estão fora da identificação estética, corpórea e morfoanatômicas instituídas (Akotirene, 2019, p. 67). 
cabelo etc., e não queria mais ser um traveco, um putão, pois eu era uma mulher, mulher de verdade (Entrevista, 5 de novembro de 2017).

Daniel disse ter convivido com gays homens, gays e mulheres cis, mas não sentia se encaixar junto deles. Quando conheceu uma amiga trans, teve mais informações e relata:

... Descobri que tudo era muito difícil, ainda mais quando não se tem muitas condições financeiras. Mas consegui fazer a cirurgia de readequação genital há uns dois anos atrás; antes disso, retirei as mamas, que era o que mais me incomodava, e hoje vivo realizado com meu corpo" (Entrevista, 30 de outubro de $1^{\text {o }}$ de novembro de 2017).

Pontes e Silva (2018) refletem o quanto o termo "transição é central para pensar o corpo como superfície flexível e vai ganhando destaque na medida em que permite passar ao registro maleável no qual contornos corporais, que se traduzem em diferenças de gêneros, são agenciados pelas(os) interlocutoras(es)" (p. 401). O gênero é constituído nas relações sociais, passível de determinações históricas e políticas, nas quais o corpo, enquanto materialidade, se impõe sobre o biológico ou qualquer normativa (Aran \& Murta, 2009).

Além das mudanças no corpo, que concretizaram transformações desejadas em relação à sua identidade de gênero, os entrevistados mencionaram que também procederam a retificação do nome civil, avaliando-a como um processo demorado e burocrático, mas que traz importantes repercussões na vida cotidiana, com direitos sociais mais alargados do que o uso do nome social. Carla ingressou no mundo do trabalho em estágio numa empresa de software com 19 anos como homem e, aos 20 anos, começou a realizar a transição. Após dois anos de estágio foi efetivada como programadora, mas, após quatro meses, pediu demissão porque os assédios tornavam insustentável sua permanência, como na insistência em chamá-la pelo nome de registro, negando o nome social existente.

Betina explicita que usou bastante o nome social - com ou sem carteirinha - desde os 18 anos:

... Porém ele te limita, porque não é tudo que tu podes fazer com ela, mas nos meus empregos no crachá sempre vinha meu nome social, nos postos de saúde, porém eu não podia fazer compras com aquele nome, apenas com o nome de batismo (Entrevista, 5 de novembro de 2017).

Diante dessas contingências, compartilha: "Resolvi entrar com os papéis para mudar meu nome de batismo, até porque acho horroroso esse tal de nome social. Então, mudei os documentos, já tenho RG novo" (Betina, entrevista, 5 de novembro de 2017). Ana considera que tanto a troca do nome quanto a cirurgia.

. . . são fatores indispensáveis para que eu me tornasse hoje quem sou, uma mulher de verdade. Foi a afirmação de tudo que eu busquei durante a minha vida e, hoje, consigo trabalhar, estudar e fazer tudo como qualquer outra mulher, sem que haja qualquer constrangimento de minha parte ou dos outros comigo (Entrevista, 8 de novembro de 2017).

Carla fez a troca do nome de registro há três anos, sendo "preciso anexar laudo psiquiatra, atestando a transexualidade, alguns outros documentos e declarações de pessoas que te conhecem como sendo de tal gênero. Mas acho o nome social ótimo, pois evita muito constrangimento, eu usava no trabalho, na faculdade, em hospitais" (Entrevista, 16 de novembro de 2017). Conforme informado na introdução, no Brasil, é permitido alterar o nome de registro para o nome social ${ }^{10}$ a

10 Ver Decreto no 8727 de 28 de abril de 2016 que dispõe sobre o uso do nome social no Brasil https://presrepublica.jusbrasil.com.br/legislacao/330064041/decreto-8727-16 (Presidência da República, 2016). 
partir do requerimento em instituições públicas, passando a ser chamada/o pelo nome com o qual se identifica.

Betina e Carla mencionaram a demora de até dois anos para a mudança de nome nos registros, o que motivou a contratação de advogados para tornarem o processo mais célere. Vidal e Bastos (2018) explicitam que a demora no estabelecimento de prazos para os procedimentos de alteração de nome e gênero, assim como os documentos necessários para tanto, "perpetua a ascensão de moralidades diversas, ocultadas e reiteradas sob o véu das justificativas jurídicas, bem como obsta a efetivação do procedimento diante da suposta impossibilidade de realizá-lo por ausência de normatização”. Daniel considera que a troca do nome

... facilita muito as coisas na vida. Antes eu usava o nome social, mas como ele não é aceito para tudo, sempre acontecia alguma coisa que expunha a minha situação. Hoje, consigo viver tranquilamente e poucas pessoas sabem da minha história. Eu também não saio contando, pois não vejo necessidade" (Entrevista, 31 outubro e $1^{\circ}$ novembro de 2017).

Em investigação realizada por Kaeffer et. al. (2016) com duas transexuais, os relatos identificam constrangimentos pelo uso de crachás no contexto de trabalho e listagem em prova de vestibular, nos quais não era observado o nome social, justificado por não observar os documentos jurídicos, já que as profissionais ainda não haviam conseguido mudança no registro civil. Nesse sentido, a consonância com identidade de gênero para sujeitos transexuais em diferentes processos de identificação é uma condição de dignidade e cidadania, o que juridicamente tornou-se possível com a mudança do prenome e sexo nos documentos civis sem necessidade de ação judicial (STF, 2018), havendo indicação de que o processo de troca progressivamente será mais célere, favorecendo a conquista da identificação que foi avaliada como importante pelos/as entrevistados/as. Viana (2018) considera que o reconhecimento pelo STF da possibilidade de retificação, por meio de ato meramente cartorial, do registro civil de pessoas transexuais e travestis no Brasil, explicita avanços mas

... com muitas fragilidades, o que nos convida, no campo jurídico, a uma imersão mais profunda nas políticas e nos estudos de gênero e sexualidade para que possamos avançar juntos em direção a um mundo mais coabitável e a vidas que mereçam serem vividas (último parágrafo).

A importância da mudança do registro civil na trajetória do/as participante/s indica a potencialidade de ações de reconhecimento pelo Estado que instaura (ou não) territórios de acesso aos direitos e exercício da cidadania.

\section{Percursos profissionais}

A investigação buscou compreender as singularidades dos percursos profissionais do/as participante/s. Betina morou por 21 anos na Europa, e, sobre sua vida antes de sair do Brasil, diz: "fiz de tudo um pouco, inclusive me prostituí, não tenho vergonha de contar, pois tudo é um aprendizado. Fiz muitas coisas consideradas erradas pela sociedade, mas foi daí que tirei meu sustento e consegui ir para o exterior" (Entrevista, 5 de novembro de 2017). Iniciou cedo no mundo do trabalho, com 10 anos, no restaurante da família, e depois participou do Programa Jovem Aprendiz, onde "Meus chefes queriam me dar lição de moral e dizer que eu deveria me comportar como um homem que deveria honrar as minhas cuecas" (Entrevista, 5 de novembro de 2017). Mais tarde, foi expulsa de casa pela mãe e teve que ir morar na rua com uma travesti que havia conhecido, se prostituindo para se sustentar. Em sua história de vida, entrecruzam-se questões familiares e sociais que possivelmente incidiram sobre sua situação: é a única entre as participantes que não atua em 
atividade relacionada com a sua formação, pois trabalha como operadora de caixa em um supermercado, considerando que "É um trabalho como outro qualquer, mas acho que tenho capacidade para mais" (Entrevista, 5 de novembro de 2017).

Ana (Entrevista, 8 de novembro de 2017), considera não ter tido dificuldades em sua trajetória profissional após a transformação e afirma que sua condição de trans nunca foi um empecilho na busca e na obtenção de um emprego. $O$ viés de classe social se explicita no percurso de formação universitária, que foi realizada com dedicação exclusiva por Ana: "Felizmente, pude estudar e terminar meus estudos para, depois, procurar emprego. Sou doutora em psicologia, e já exerço minha profissão há bastante tempo. Por isso, me considero diferente das demais pessoas trans, porque não tive essas dificuldades".

A possibilidade de contar com apoio familiar também se diferencia, bem como a permanência no ambiente educacional, e o escopo da área de estudos e trabalho:

... Quando eu fui em busca de oportunidades, já tinha passado por toda a transformação no meu corpo, na aparência e no nome, e essa área que trabalho, ela é mais aberta a esses assuntos, é melhor aceita. Então, não tive problema algum (Ana, 8 de novembro de 2017).

A cisnormatividade é identificada quando reconhece possíveis facilidades ao inserir-se profissionalmente após a transição, pois "poucas pessoas sabem que sou trans e muitas não acreditam ... devido às minhas condições físicas: mãos pequenas, estatura baixa”. Para Pontes e Silva (2018), "se o objetivo último da transição a possibilidade de 'passar por cis', a experiência da passabilidade como horizonte normativo acaba por definir e aplicar valores aos corpos e, por conseguinte, aos próprios sujeitos" (p. 403).

Carla ingressou em seu primeiro emprego como estagiária aos 19 anos e, depois, foi efetivada como programadora, sentindo-se obrigada a pedir demissão após quatro meses neste cargo, porque o assédio estava insustentável por parte dos colegas. Comenta que, nos demais lugares onde trabalhou, por já ter feito todo o processo de transição, muitas pessoas não sabiam que era trans, o que reduziu a vivência de situações de discriminação. Seu percurso profissional é marcado por diversas mudanças, mas mantendo-se na área de TI. Algumas ocorreram por sua iniciativa, em busca de melhores oportunidades e condições de trabalho, outras, pelo ambiente insustentável para sua permanência em razão de posturas e atitudes relativas à discriminação presentes no contexto organizacional.

O trabalho informal e a prostituição foram as modalidades de geração de renda identificadas por Kaeffer et al. (2016) na pesquisa com trabalhadoras transexuais, havendo trajetórias de escolarização com interrupções e mesmo abandono, justamente em função das dificuldades de expressão de sua diferença no ambiente educacional. Na presente investigação, o fato do/as profissional/is possuírem ensino superior ampliou a empregabilidade e as opções de exercício profissional. Contudo, o reconhecimento da transexualidade nas empresas é fator de exclusão como relatado pelo/as entrevistado/as, podendo ser vivido como algo manifesto ou encoberto, mas percebido em seus efeitos subjetivos.

\section{Discriminação nas vivências de trabalho}

A dimensão de experiências discriminatórias mesmo em profissionais que possuem condições sociais diferenciadas é analisada nesta categoria. Daniel (Entrevista, 31 outubro e $1^{\text {o }}$ novembro de 2017) relatou que "antes de trabalhar onde estou atualmente, tive algumas dificuldades em conseguir emprego, mas alguns eu não tenho certeza se foram ou não em função de eu ser trans, talvez nunca eu venha a ter certeza". O caráter velado da discriminação foi mencionado também pelas mulheres 
trans entrevistadas, descrito posteriormente. Mas o participante situou um episódio no qual ficou evidente a transfobia durante processo seletivo em empresa multinacional:

Já havia feito as entrevistas todas e estava tudo certo para eu começar. Eu estava muito feliz, era uma ótima oportunidade e um salário muito bom. Estava tudo certo, a vaga era minha, tanto que me pediram para levar a documentação, eu não havia informado que era trans. Talvez eu devesse ter dito isso no início, mas como já sou tão acostumado comigo assim, que não senti necessidade. Não foi consciente isso, não foi na intenção de provar minhas qualificações para a vaga. Quando entreguei os documentos e viram meu antigo nome - hoje já fiz a troca, mas antes tinha um nome feminino então eles mudaram completamente, ficou escrito na cara deles - . . começaram a fazer várias perguntas, colocar vários empecilhos - e mudou completamente o tratamento comigo antes de saber que eu era trans. Uma mudança brusca, chocante. Então, ficou muito claro que era um caso de transfobia, e foi dentro do setor de Recursos Humanos mesmo (Daniel, 31 outubro e $1^{\underline{O}}$ novembro de 2017).

No emprego atual, Daniel não enfrenta problemas, pois considera uma empresa muito menor e mais aberta para a diferença, afirmando que:

Tive e tenho oportunidade de crescer ainda mais na empresa. Assim que entrei não havia nada voltado para nenhum tipo de diversidade. Estou conseguindo incluir aos poucos isso e, em breve, farei a empresa evoluir mais em questão de gênero, mas o nome social já é possível fazer uso lá (Entrevista, 31 outubro e $1^{\circ}$ novembro de 2017 ).

Comenta que já fez a troca do nome e, habitualmente, não se nomeia como transexual, "apenas pessoas mais próximas é que sabem disso, para todas as outras sou um colega homem como qualquer outro". Benevides e Nogueira (2020) comentam que há uma invisibilidade dos homens trans e pessoas transmasculinas, impedindo levantamento e análise de dados. Essa parcela da população trans possui maior escolaridade - pelo menos $80 \%$ concluiu o ensino médio - e estima-se que seja a maior presença nos empregos formais, com índices superiores a 70\%.

Betina remete à vida familiar os acontecimentos mais agressivos relacionados a sua condição trans. Contudo, relata que algumas pessoas ficavam incomodadas com o seu crescimento profissional, como na experiência que viveu em Portugal, onde trabalhava numa rede fastfood. Começou como garçonete e, logo, conquistou a posição de gerente: "porém, com isso, despertou a raiva e a inveja dos colegas que já trabalhavam há algum tempo e que não conseguiram oportunidade de crescimento, isso porque não se esforçavam" (Entrevista, 5 de novembro de 2017). Declara que sofreu discriminação e ofensas nesse local pelos clientes africanos:

Por muitas vezes fui ofendida por eles, o que me surpreendeu muito, pois eles, como negros, sofriam muito preconceito ... Falei para eles num dia que me irritei e resolvi dar um basta naquela situação. ... Ao se referir a mim, não me chamavam por meu nome, mas sim usavam o termo "paneleiro" e era sempre assim "Oh paneleiro faz isso, faz aquilo". Em Portugal, paneleiro significa gay. . . . Até que resolvi enfrentá-los, justamente comparando o que estavam fazendo comigo ao racismo que todos eles sofriam diariamente. Depois disso, as coisas melhoraram bastante (Entrevista, 5 de novembro de 2017).

Betina assinala uma dimensão importante, relativa às posições de liderança, pois considera que:

. . são raros nos casos de pessoas transgêneras em cargos mais altos de gestão. Para gays é mais fácil, mas para transgêneros, confesso que nunca conheci ninguém transgênero num cargo de gestor ou supervisor ou gerente, em uma grande empresa ou pequena, que fosse" (Entrevista, 5 de novembro de 2017). 
Tal discriminação também pode ocorrer entre grupos ditos minoritários, como relatado pela participante, sendo importante o assinalamento que possibilita a emergência de relações sociais pautadas por ética que realmente reconheça as diferenças.

Carla menciona que vivenciou episódios de assédio em empresas e exclusão de algumas oportunidades de emprego. Como terceirizada em uma empresa em que sofria assédio cotidianamente, o chefe pediu seu desligamento alegando que não tinha atendido uma demanda no prazo. Resolveu procurar o comitê de ética para denunciar e, sobre isso, relata: “. . me chamaram para conversar, falaram que iriam conversar com os agressores, mas eu nunca soube se fizeram isso. Um mês depois, me desligaram" (Carla, 16 de novembro de 2017).

Posteriormente, em audiência trabalhista contra a empresa, ouviu o juiz indagar ao seu exgestor se já havia solicitado o desligamento de alguém por esse mesmo motivo, ao que ele respondeu negativamente. Contudo, houve empresas no setor de TI em que, mesmo mencionando a condição transexual, conseguia a vaga. A entrevistada assinala a dupla dificuldade: a área de TI é predominantemente masculina, havendo restrições para o ingresso e reconhecimento de competência de mulheres, sobrepondo-se às discriminações que podem lhe ser remetidas. Para Diniz et al. (2013), o assunto gênero ainda é pouco discutido nas organizações, mesmo naquelas que dizem possuir uma política de diversidade, prevalecendo ainda atitudes discriminatórias institucionalizadas. Revela-se, assim, o assimilacionismo que supostamente reconhece e integra sujeitos às instituições sociais, mas conforma-os a partir de elementos heteronormativos, impedindo a expressão e a legitimidade das diferenças.

Andrade e Vasconcellos (2018) assinalam ações que poderiam alterar o quadro de desemprego da população trans: aprovação de legislações de cotas e de reconhecimento da identidade de gênero no contexto empresarial, capacitação dos serviços de RH e garantia do respeito à identidade de gênero no ambiente de trabalho. Ampliando a análise de questões estruturais presentes no escopo em discussão, Pontes e Silva (2018) argumentam que a passabilidade, em interação com outros marcadores como classe, raça e etnia, delimita o acesso a recursos simbólicos, afetivos e técnicos, "enfatizando o caráter contextual da dissidência e das correlações centro-margem nas normas de gênero" (p. 410). As situações de discriminação relembradas pelo/as profissional/is são evidências de que a inserção não assegura o pertencimento e o efetivo reconhecimento dos trabalhadores nas organizações.

\section{Considerações Finais}

A investigação qualitativa e de cunho exploratório teve por objetivo analisar as experiências de profissionais transexuais inseridos formalmente no mundo do trabalho, considerando o contexto predominante de informalidade e atividades ligadas à prostituição dessa população. A pesquisa, de característica qualitativa exploratória, foi realizada por meio de entrevistas com três mulheres transexuais e um homem trans que possuem vínculos formais em empresas, residentes em diferentes cidades brasileiras.

As narrativas aludem que, além do gênero, a empregabilidade das/o profissionais é permeada por aspectos relativos à escolaridade, o que circunscreve os percursos de trabalho analisados. A não identificação da transexualidade no ambiente laboral é percebida como um facilitador, em razão da passibilidade e cisnormatividade dos corpos; contudo, foram vivenciadas situações de discriminação em razão de atitudes transfóbicas em processos seletivos e no contexto laboral. A mudança no registro civil e a abertura à diferença nas empresas são defendidas pelo/as participantes como decisivas, assinalando-se como questões estruturais a importância de ações afirmativas que incidam no âmbito educacional e no mundo do trabalho. 
A contribuição pretendida pela investigação reside na visibilidade das/os trabalhadoras/es que vivenciam o mundo do trabalho a partir de condições significativamente distantes da parcela majoritária da população trans, podendo ensejar a reflexão sobre a permanência de contextos discriminatórios e excludentes, pois persistem regramentos relacionados à heteronormatividade nas organizações. A subjetividade das/os profissionais participantes da pesquisa mostra-se avaliada, nos cânones institucionais, pela prevalência da dimensão do gênero no trabalhador, questão que não está em cena para as/os cisgêneras/os.

A dificuldade inicial para identificar e, posteriormente, acessar as/o profissionais/l trans com vínculos formais de trabalho alude à restrita inserção dessa população no contexto empresarial, colocando-se como uma limitação da pesquisa. Percebeu-se, mesmo diante daqueles que se disponibilizaram a participar, que a rememoração ou mesmo a comunicação de experiências não é algo fácil na relação com o pesquisador. Considerando essa condição na interlocução, houve níveis diferentes de partilha diante do convite para falarem sobre suas vivências no mundo do trabalho, o que implicou redução de elementos em algumas dimensões analisadas.

Mesmo identificando contingências que reduziram a potencialidade da discussão acerca da interseccionalidade presente no contexto abordado, avalia-se que os acontecimentos e impressões das/do profissionais/l são potentes para dimensionar realidades silenciadas e invisibilizadas no ambiente social de tensões persistentes diante das diferenças. Sugere-se que, em futuras pesquisas, sejam investigadas/os profissionais que possuam níveis médios de escolaridade e sejam analisados aspectos raciais, pois são perspectivas que incidem nos percursos de trabalho das/os profissionais trans, avançando em questões que foram tangenciadas pelo presente artigo.

\section{Referências}

Akotirene, C. (2019). Interseccionalidade. Pólen.

Almeida, C. B. de, \& Vasconcellos, V. A. (2018). Transexuais: transpondo barreiras no mercado de trabalho em São Paulo? Direito GV, 14(2), 303-333.

Andrade, L. N. de (2012). Travestis na escola: assujeitamento e resistência à ordem normativa. [Tese de Doutorado. Universidade Federal do Ceará].

Arán, M., \& Murta, D. (2009). Do diagnóstico de transtorno de identidade de gênero às redescrições da experiência da transexualidade: uma reflexão sobre gênero, tecnologia e saúde. Physis: Revista de Saúde Coletiva, 19(1), 15-41.

Associação Brasileira de Lésbicas, Gays, Travestis e Transexuais (2016). Pesquisa nacional sobre o ambiente educacional no Brasil: as experiências de adolescentes jovens, lésbicas, gays, bissexuais, travestis e transexuais em nossos ambientes educacionais. http://www.grupodignidade.org.br/wp-content/uploads/2016/03/IAE-Brasil-Web-3-1.pdf

Associação Nacional de Travestis e Transexuais (2020). Assassinatos contra travestis e transexuais brasileiras em 2020. Boletim no 05/2020-01 de janeiro a 31 de outubro de 2020. https://antrabrasil.files.wordpress.com/2020/11/boletim-5-2020-assassinatos-antra.pdf

Bardin, L. (2010). Análise de conteúdo. 4⿳亠丷a ed. Edições 70.

Benevides, B. (2018). Mapa dos assassinatos de travestis e transexuais no Brasil em 2017. Associação Nacional de Travestis e Transexuais. https://antrabrasil.files.wordpress.com/2018/02/relatc3b3rio-mapa-dos-assassinatos-2017-antra.pdf

Benevides, B. G., \& Nogueira, S. N. B. (2019). Mapa dos assassinatos de travestis e transexuais no Brasil em 2018. Associação Nacional de Travestis e Transexuais, Instituto Brasileiro Trans de Educação. https://antrabrasil.files.wordpress.com/2019/12/dossie-dos-assassinatos-e-violencia-contra-pessoas-trans-em2018.pdf 
Benevides, B. G., \& Nogueira, S. N. B (2020). Mapa dos assassinatos de travestis e transexuais no Brasil em 2019. Expressão Popular, Associação Nacional de Travestis e Transexuais, Instituto Brasileiro Trans de Educação. https://antrabrasil.files.wordpress.com/2020/01/dossic3aa-dos-assassinatos-e-da-violc3aancia-contra-pessoastrans-em-2019.pdf

Bento, B. (2014). Nome social para pessoas trans: Cidadania precária e gambiarra legal. Contemporânea: Revista de Sociologia da UFSCar, 4(1), 165-182.

Carpulovisky, A. (2020, 04 fevereiro). Passabilidade: A aparência também como barreira para trans no trabalho. \#Colabora. https://projetocolabora.com.br/ods5/passabilidade-a-aparencia-tambem-como-barreira-para-transno-mercado-trabalho/

Carrieri, A. P., Souza, E. M., \& Aguiar, A. R. C. (2014). Trabalho, violência e sexualidade: Estudo de lésbicas, travestis e transexuais. Revista de Administração Contemporânea, 18(1), 78-95.

Catraca Livre. (2020, 29 de outubro). Glossário LGBTQIA+: entenda cada letra da sigla e termos comuns. \# Catraca Livre. Glossário LGBTQIA+: entenda cada letra da sigla e termos comuns (catracalivre.com.br).

Conselho Federal de Psicologia (2018). Resolução $n^{\underline{o}}$ 1, de 29 de janeiro de 2018. https://site.cfp.org.br/wpcontent/uploads/2018/01/Resolu\%C3\%A7\%C3\%A3o-CFP-01-2018.pdf

Diniz, A. P. R., Carrieri, A. P., Gandra, G., \& Bicalho, R. A. (2013). Políticas de diversidade nas organizações: As relações de trabalho comentadas por trabalhadores homossexuais. Revista Economia $\mathcal{F}$ Gestão, 13(31), 93-114.

Flick, U. (2013). Introdução à metodologia de pesquisa. Penso.

Gil, A. C. (2012). Métodos e técnicas de pesquisa social. 6ª ed. Atlas.

Kaeffer, K. K., Ramos, F. G., Alves, A. L., \& Tonon, L. (2016). A transexualidade e o mercado de trabalho formal de trabalho: Principais dificuldades para a inserção profissional. Anais IV Congresso Brasileiro de Estudos Organizacionais. SBEO https://anaiscbeo.emnuvens.com.br/cbeo/article/viewFile/52/44

Lucena, S. G. (2018). Análise da passabilidade como mecanismo de proteção as experiências trans. In A. F. Dias, E. F. Santos, M. H. S. Cruz, J. M. Oliveira (Orgs). Conqueer: I Conferência Internacional de Estudos Queer (p. 156). Realize. https://editorarealize.com.br/artigo/visualizar/40201

Miskolci, R., \& Pelúcio, L. (2007). Fora do sujeito e fora do lugar: reflexões sobreperformatividade a partir de uma etnografia entre travestis. Gênero, Niterói, 7(2), 255-267.

Nogueira, S. (2017). Da negação da identidade de gênero na imprensa brasileira. In S. N. B. Nogueira, T. A. Aquino \& E. A. Cabral, (Orgs). A Geografia dos Corpos das Pessoas Trans (pp 23-28). Rede Trans Brasil. http://redetransbrasil.org.br/wp-content/uploads/2019/01/A-Geografia-dos-Corpos-Trans.pdf

Oliveira, J. W. de, Rosato, C. M., Nascimento, A. M.R., \& Granja, E. (2018). "Sabe a minha identidade? nada a ver com genital": vivências travestis no cárcere. Psicologia: Ciência e Profissão, 38(spe2), 159-174.

Pontes, J. C., \& Silva, C. G. (2018). Cisnormatividade e passabilidade: Deslocamentos e diferenças nas narrativas de pessoas trans. Periódicus, 8(1), 396-417.

Prado, M. A. M. (2016, 18 de novembro). Representação local e política partidária: Candidaturas transexuais e travestis no Brasil. Dossiê SPW - Transexuais e travestis nas eleições de 2016. Observatório de Sexualidade e Política. https://sxpolitics.org/ptbr/representacao-local-e-politica-partidaria-candidaturas-transexuais-e-travestis-nobrasil/6884

Presidência da República (2016). Decreto no 8.727, de 28 de abril de 2016, Presidência da República. http://www.planalto.gov.br/ccivil_03/_ato2015-2018/2016/decreto/d8727.htm 
Rondas, L. de O., \& Machado, L. R. de S. (2015). Inserção profissional de travestis no mundo do trabalho: Das estratégias pessoais às políticas de inclusão. Pesquisas e Práticas Psicossociais, 10(1), 192-205.

Sexuality Policy Watch. (2020, 16 de novembro). Negras e trans se destacam nas eleições enquanto extrema-direita cai. https://sxpolitics.org/ptbr/negras-e-trans-se-destacam-nas-eleicoes-enquanto-extrema-direita-cai/11402

Siqueira, M. V. S., Saraiva, L. A. S., Carrieri, A. de P., Lima, H. K. B. de, \& Andrade, A. J. de A. (2009). Homofobia e violência moral no trabalho no Distrito Federal. Organizações $\mathcal{E}$ Sociedade, 16(50), 447-461.

Supremo Tribunal Federal. (2018) ADI 4275/ DF, Rel. Min. Marco Aurélio, 01/03/2019. http://portal.stf.jus.br/processos/detalhe.asp?incidente $=2691371$

Teixeira, F. do B. (2012). Histórias que não têm era uma vez: As (in)certezas da transexualidade. Revista Estudos Feministas, $20(2), 501-512$.

Viana, I. C. (2018, 21 de março). Supremo Tribunal Federal: Entre o importante avanço para a cidadania trans no Brasil e a permanência de uma visão essencialista do gênero. Observatório de Sexualidade e Política. https://sxpolitics.org/ptbr/8257-2/8257

Vianna, C. P. (2015). O movimento LGBT e as políticas de educação de gênero e diversidade sexual: Perdas, ganhos e desafios. Educação e Pesquisa, 41 (3), 791-806.

Vidal, J. S., \& Bastos, S. P. (2018, 06 de agosto). STF e o direito à identidade de gênero: fragilidades, disputas e projeções em um campo incerto. Observatório de Sexualidade e Política. https://sxpolitics.org/ptbr/stf-e-o-direito-aidentidade-de-genero-fragilidades-disputas-e-projecoes-em-um-campo-incerto/8721.

World Professional Association for Transgender Health. (2012). Standards of care for the Health of Transseexual, Transgender, and Gender Nonconforming People. $\quad 7^{\text {a }}$ ed. https://www.wpath.org/media/cms/Documents/SOC\%20v7/SOC\%20V7_English2012.pdf?_t=1613669341

Endereço para correspondência

dmziliotto@hotmail.br
Recebido em: 10/03/2020

Revisado em: 24/07/2021

Aprovado em: 02/08/2021 